\title{
Yield potential of world wheat based on ARIMA model under global warming
}

\section{CAI CHENG-ZHI ${ }^{*}$, CAO WEN-FANG ${ }^{2}$, ZENG XIAO-SHAN $^{3}$, ZUO JIN $^{3}$, XIAO DAN $^{4}$, LIAO CONG- JIAN $^{1}$ and KANWAL WAQAR ${ }^{5}$}

\author{
${ }^{I}$ Economic Institute, Guizhou University of Finance and Economics, Guiyang 550025, PRC \\ ${ }^{2}$ Department of Land, Environment, Agriculture and Forestry - University of Padova Agripolis \\ viale dell'Università 16, Italy \\ ${ }^{3}$ Guizhou Ecological Meteorology \& Satellite Remote Sensing Centre, Guiyang 550002, PRC \\ ${ }^{4}$ Key Lab of Economic System Simulation, Guizhou University of Finance and Economics, Guiyang 550025, PRC \\ ${ }^{5}$ International Centre for Integrated Mountain Development, Kathmandu, Nepal \\ *Corresponding author: caichengzhi@mail.gufe.edu.cn
}

\begin{abstract}
As the most important food crop across the world, with continuous increase in world population and steady declining farmlands, wheat has been attracting academic attention for improving its yield or potential in the future particularly under global warming. Therefore, analyzing the yield or potential of wheat at global level relevant to greenhouse gas effect is of great significance to direct future production of wheat in the world. However up to now, there are relatively few reports on potential yield of world wheat projected using 'time series' approach like ARIMA (Auto-regressive Integrated Moving Average) model. Thus in this paper, the crop potential yield of world wheat during 2019 to 2028 is projected using ARIMA model based on the yields from 1961 to 2018 . Our results show that during 2019 to 2028 , the average yields of world wheat are projected to increase from 3569 to $4257 \mathrm{~kg} \mathrm{ha}^{-1}$ while top yields of world wheat from 9852 to $11246 \mathrm{~kg} \mathrm{ha}^{-1}$. Annual global mean temperatures are projected to increase from 15.05 to $15.31^{\circ} \mathrm{C}$. Global warming exerts positive effect on average yield of world wheat while negative effect on the top yield in 1961 to 2018 and 2028. Our study concluded that for world wheat production in 2019 to 2028 , the opportunities for improving production should be mainly dependent on the advantage of highyield countries as the yield is still in low place before the turn-point of $S$-shaped curve in long-term trend affected partly by greenhouse gas effect.
\end{abstract}

Key words: World wheat; yield potential; ARIMA model; global warming.

As the most important food crop across the world, with continuous increase in world population and steady declining farmlands, wheat has been attracting academic attention for improving its yield or potential in the future particularly under global warming. Recent studies to determine the wheat yield and its potential through modelling have provided a number of important incites e.g. The accuracy and efficiency of optimization algorithms was done by comparing the POWELL and SCE-UA method to predict the regional winter wheat yield, the comparison shows that POWELL algorithm performs better than SCEUA due to the high assimilation accuracy and much higher running efficiency (Tian et al., 2013). The CERES-Wheat model which was used for estimating the regional production of wheat in Bihar of India, revealed the percentage deviation of $+/-4.0 \%$ of forecasted yield from the actual (Singh et al., 2017). The impact of climate change on wheat yield in Myandoab of Iran was simulated by using SWAP, which showed that negative impact of temperature increase has dominated the positive impact of $\mathrm{CO}_{2}$ concentration, hence decline in yield (Azad et al., 2018). A linear mixed-effect model was presented to predict wheat yield in the northern grain-growing region of Australia, demonstrating moderate predictive accuracy at a field scale, with an average root mean square error (RMSE) of $0.79 \mathrm{Mg}$ ha (Lai et al., 2018). The DSSAT model, integrated with calibrated Hargreaves ET model and dynamic crop coefficient, was run with the generated weather data to predict the potential yield and crop water requirement of winter wheat in the Huang-HuaiHai Plain in China; the models suggested that the spatial distribution of potential yield in the future was characterized by an increasing trend from the northwest inland to the southeast coast (Tang et al., 2018). The APSIM model was parameterised for local soils and climate, furthermore calibrated for rice and wheat growth, phenology and yields in Pakistan by using experimental data sets; the study 
showed that farmers have currently achieved only $48 \%$ $56 \%$ potential of wheat in Narowal and Gujranwala, respectively (Khaliq et al., 2019). An improved CarnegieAmes-Stanford approach (CASA) model was coupled with time-series satellite remote sensing images to estimate winter wheat yield in China, which presented that the estimated yield of winter wheat based on remote sensing images is consistent with the ground-measured yield, with $\mathrm{R}^{2}$ of 0.56 , RMSE of $1.22 \mathrm{tha}^{-1}$, and an average relative error of $-6.01 \%$ (Wang et al., 2019). The impacts of climate change on wheat yield in the Huang-Huai-Hai Plain of China by 2099 was simulated by using DSSAT-CERES-Wheat model, which demonstrated that the effects of increasing thermal resources were counteracted by the aggravated water deficits caused by the increase in temperature (Qu et al., 2019). Possible impacts of three climate variables on spring wheat yield in North Dakota of USA was assessed by building a regression model, which showed that the percentage deviation of error for the model is approximately $+/-30 \%$ in most of the years (Mistry and Bora, 2019). The impact of weather factors on the achieved wheat yields was analyzed by using a set of panel data on selected Serbian municipalities in 2000 to 2013, which displayed that the growth of water deficit by $0.1 \mathrm{~mm}$ in the period November 15 to April 1 resulted in 175 $\mathrm{kg} \mathrm{ha}^{-1}$ lower yields while in the period April 1 to May $15 \mathrm{did}$ in $45 \mathrm{~kg} \mathrm{ha}^{-1}$ lower yields (Jelocnik et al., 2019). The derived phenological metrics for vegetation indices (VIs) and surface reflectance's (SRs), namely peak, area under curve (AUC), and fitting coefficients from a quadratic function, were used for building empirical regression winter wheat models at a regional scale in Ukraine for three years (2016-2018), yielding a RMSE of $0.201 \mathrm{tha}^{-1}(5.4 \%)$ and coefficient of determination $\mathrm{R}^{2}$ of 0.73 on cross-validation (Skakun et al., 2019). Feng et al. (2019) developed a hybrid model by incorporating the APSIM model outputs and growth stagespecific ECEs indicators (i.e. frost, drought and heat stress) into the Random Forest (RF) model using multiple linear regression (MLR) model as a benchmark, and suggested that the APSIM + RF hybrid model could explain $81 \%$ of the observed yield variations in the New South Wales wheat belt of south-eastern Australia. The APSIM + RF hybrid model had a 33\% improvement in modelling accuracy compared to the APSIM model alone and $19 \%$ improvement compared to the APSIM + MLR hybrid model. Zhang et al. (2019) investigated the applicability of the Simple Algorithm for Yield Estimate (SAFY) model for estimating winter wheat dry shoot biomass and grain yield in Guanzhong Plain of China, using two growing seasons field data from different irrigation scenarios, and pointed out that the leaf area index (LAI) could be reasonably well simulated, with a minimum RMSE of 0.11. DSSAT (decision support system for agro-technology transfer) was validated for predicting growth and yield of wheat in Iran under a diverse semi-arid climate (2 years with diverse climates) and different irrigation strategies, planting methods, and nitrogen rates, which indicated that water stress and inappropriate weather especially during the stem elongation influences the grain yield remarkably without noticeable effect on straw yield (Mehrabi et al., 2019). A field study was conducted to estimate the regional wheat yield in Pakistan by integrating remotely sensed soil moisture index into CERES-Wheat model, reaching a good agreement between observed and simulated values of grain yield (RMSE $=284.8 \mathrm{~kg} \mathrm{ha}^{-1}$ ), which showed estimated mean yield of $2979 \mathrm{~kg} \mathrm{ha}^{-1}$ being $5.2 \%$ higher than the yield reported by Crop Reporting Service in Punjab (Fahad et al., 2019). A light use efficiency model (EC-LUE) was used for estimating winter wheat yield in Kansas of USA with $30-\mathrm{m}$ spatial resolution Landsat data, which indicated that the EC-LUE model combined with wheat variety data can effectively capture the spatial variations of winter wheat yields, and specifically proposed method significantly improves model simulation performance for the inter-annual variation of yields during 2008-2017 and explains $82 \%$ of the interannual yield variation (Dong et al., 2020); and so on.

As discussed above, there are rich research reports on the crop yield or potential of wheat being modeled and partly related to climatic factor, but most are based on the theory of production function for wheat yield, of specific variety, from static biological dimension and at local or regional level, while few are based on (stationary) stochastic process for generic wheat from dynamic evolutionary dimension and at global level. Thus in this paper, we use 'time series' approach ARIMA (Auto-regressive Integrated Moving Average) model based on stationary stochastic process integrating global warming effect to estimate yield or potential of world wheat in the future basing the projections on historic performance, and aim to provide information on directing the production of wheat in the world facing global food insecurity deteriorated by the contradiction between the increase of human demand and the decrease of arable land.

\section{MATERIALS AND METHODS}

\section{Datasets}

Annual global mean temperature $\left({ }^{\circ} \mathrm{C}\right)$, historic or statistical data of average and top yields (at national level) of world wheat from 1961 to 2018 is used for projecting and analyzing their futures under global warming.

As shown in Table 1, from 1961 to 2018: average 
Table 1: Global mean temperature $\left({ }^{\circ} \mathrm{C}\right)$, average and top yields of world wheat $\left(\mathrm{kg} \mathrm{ha}^{-1}\right)$ from 1961 to 2018

\begin{tabular}{|c|c|c|c|c|c|c|c|c|c|}
\hline Year & $\begin{array}{l}\text { Global } \\
\text { temp. }\end{array}$ & $\begin{array}{l}\text { Average } \\
\text { yield }\end{array}$ & $\begin{array}{l}\text { Top } \\
\text { yield }\end{array}$ & $\begin{array}{l}\text { Country of } \\
\text { top yield }\end{array}$ & Year & $\begin{array}{l}\text { Global } \\
\text { temp. }\end{array}$ & $\begin{array}{l}\text { Average } \\
\text { yield }\end{array}$ & $\begin{array}{l}\text { Top } \\
\text { yield }\end{array}$ & $\begin{array}{l}\text { Country of } \\
\text { top yield }\end{array}$ \\
\hline 1961 & 14.00 & 1089 & 4121 & Denmark & 1990 & 14.39 & 2563 & 8531 & Ireland \\
\hline 1962 & 13.82 & 1206 & 4548 & Netherlands & 1991 & 14.24 & 2444 & 7865 & Ireland \\
\hline 1963 & 13.93 & 1132 & 4196 & Netherlands & 1992 & 13.98 & 2540 & 8015 & Netherlands \\
\hline 1964 & 13.52 & 1241 & 4706 & Netherlands & 1993 & 14.11 & 2544 & 8771 & Netherlands \\
\hline 1965 & 13.55 & 1215 & 4457 & Denmark & 1994 & 14.26 & 2448 & 8067 & Netherlands \\
\hline 1966 & 13.98 & 1408 & 4275 & Denmark & 1995 & 14.61 & 2515 & 8619 & Netherlands \\
\hline 1967 & 13.65 & 1339 & 4791 & Netherlands & 1996 & 14.12 & 2577 & 8997 & Ireland \\
\hline 1968 & 13.67 & 1453 & 4814 & Denmark & 1997 & 14.46 & 2702 & 7934 & Belgium \\
\hline 1969 & 13.66 & 1417 & 4395 & Ireland & 1998 & 14.79 & 2706 & 8252 & Luxembourg \\
\hline 1970 & 13.92 & 1494 & 4546 & Netherlands & 1999 & 14.59 & 2751 & 8767 & Ireland \\
\hline 1971 & 13.67 & 1625 & 4969 & Netherlands & 2000 & 14.52 & 2722 & 9454 & Ireland \\
\hline 1972 & 13.57 & 1605 & 4570 & France & 2001 & 14.61 & 2742 & 9060 & Ireland \\
\hline 1973 & 14.02 & 1684 & 5255 & Netherlands & 2002 & 14.78 & 2755 & 8444 & Ireland \\
\hline 1974 & 13.57 & 1616 & 5733 & Netherlands & 2003 & 14.61 & 2652 & 8744 & Netherlands \\
\hline 1975 & 13.85 & 1570 & 5102 & Denmark & 2004 & 14.70 & 2943 & 9924 & Ireland \\
\hline 1976 & 13.44 & 1791 & 5437 & Netherlands & 2005 & 14.81 & 2829 & 8593 & Netherlands \\
\hline 1977 & 14.02 & 1672 & 5230 & Netherlands & 2006 & 14.72 & 2891 & 9154 & Ireland \\
\hline 1978 & 13.77 & 1933 & 6567 & Netherlands & 2007 & 14.93 & 2815 & 8497 & New Zealand \\
\hline 1979 & 13.98 & 1852 & 5938 & Netherlands & 2008 & 14.66 & 3062 & 9939 & Zambia \\
\hline 1980 & 14.08 & 1855 & 6202 & Netherlands & 2009 & 14.69 & 3037 & 9465 & Belgium \\
\hline 1981 & 14.23 & 1880 & 6701 & Netherlands & 2010 & 14.92 & 2971 & 8909 & Netherlands \\
\hline 1982 & 13.86 & 1999 & 7390 & Netherlands & 2011 & 14.64 & 3164 & 9864 & Ireland \\
\hline 1983 & 14.25 & 2126 & 7037 & Netherlands & 2012 & 14.78 & 3089 & 8925 & New Zealand \\
\hline 1984 & 13.90 & 2220 & 7885 & Netherlands & 2013 & 14.72 & 3250 & 9105 & New Zealand \\
\hline 1985 & 13.73 & 2172 & 6645 & Netherlands & 2014 & 14.80 & 3315 & 10014 & Ireland \\
\hline 1986 & 14.01 & 2321 & 7998 & Netherlands & 2015 & 15.10 & 3317 & 10668 & Ireland \\
\hline 1987 & 14.17 & 2290 & 7065 & Ireland & 2016 & 15.34 & 3405 & 9539 & Ireland \\
\hline 1988 & 14.31 & 2293 & 7765 & Ireland & 2017 & 15.14 & 3541 & 10172 & Ireland \\
\hline 1989 & 14.16 & 2373 & 7598 & Netherlands & 2018 & 14.96 & 3425 & 8960 & New Zealand \\
\hline
\end{tabular}

Source: https://www.ncdc.noaa.gov/temp-and-precip/; http://www.fao.org/faostat/en/\#data.

yields of world wheat rose more steadily than the top yields, annual global mean temperature increased in a slight fluctuation. 'Average yield' means average yield of world wheat worldwide while 'top yield' indicates top yield of specific country whose yield of wheat countrywide topped in the world in given year. For example, Danish yield of wheat countrywide topped in the world in 1961, so did New Zealand one in 2018, and so on.

\section{ARIMA modelling}

ARIMA model is a valuable approach used for projecting the futures of 'time series' variable, in which it is assumed that if a stochastic process has some numbers of unit root it can be converted to a stationary process of autoregressive moving average after same times of differencing required for producing the stationarity of series. A simplified representation of the model is $\operatorname{ARIMA}(p, d, q)$, where $p$ is the 
Table 2: The equations of five basic models for fitting average yields of world wheat from 2009 to 2018

\begin{tabular}{ll}
\hline Model & Equation \\
\hline $\operatorname{ARMA}(1,2)$ & $\ln a v e_{t}=0.019623+0.076314 \ln a v e_{t-1}+0.923686 \ln a v e_{t-2}+\varepsilon_{t}+0.469445 \varepsilon_{t-1}-0.483982 \varepsilon_{t-2}$ \\
$\operatorname{ARMA}(1,1)$ & $\ln$ ave $_{t}=0.019579+0.401460 \ln a v e_{t-1}+0.598540 \ln a v e_{t-2}+\varepsilon_{t}-0.042043 \varepsilon_{t-1}$ \\
$\operatorname{AR}(1)$ & $\ln a v e_{t}=0.019566+0.378403 \ln a v e_{t-1}+0.621597 \ln a v e_{t-2}+\varepsilon_{t}$ \\
$\operatorname{MA}(2)$ & $\ln a v e_{t}=0.019912+\varepsilon_{t}-0.683780 \varepsilon_{t-1}+0.202810 \varepsilon_{t-2}$ \\
MA(1) & $\ln a v e_{t}=0.019767+\varepsilon_{t}-0.562984 \varepsilon_{t-1}$ \\
\hline
\end{tabular}

Note: in the equations, 'ave' stands for 'average yield of world wheat'.

Table 3: The error between fitted values and actual average yields of world wheat from 2009 to 2018 (\%)

\begin{tabular}{|c|c|c|c|c|c|}
\hline Year & $\operatorname{ARMA}(1,2)$ & $\operatorname{ARMA}(1,1)$ & $\mathrm{AR}(1)$ & MA (2) & MA (1) \\
\hline 2009 & -3.97 & -3.35 & -3.48 & -5.23 & -5.56 \\
\hline 2010 & +0.26 & +0.73 & +0.59 & -1.19 & -1.56 \\
\hline 2011 & -4.15 & -3.55 & -3.68 & -5.35 & -5.70 \\
\hline 2012 & +0.26 & +0.74 & +0.61 & -1.10 & -1.49 \\
\hline 2013 & -2.93 & -2.35 & -2.50 & -4.10 & -4.50 \\
\hline 2014 & -2.84 & -2.36 & -2.51 & -4.08 & -4.50 \\
\hline 2015 & -1.10 & -0.49 & -0.65 & -2.24 & -2.66 \\
\hline 2016 & -1.62 & -1.15 & -1.29 & -2.82 & -3.26 \\
\hline 2017 & -3.61 & -3.08 & -3.22 & -4.69 & -5.14 \\
\hline 2018 & +1.69 & +2.19 & +2.04 & +0.53 & +0.03 \\
\hline Mean & -1.80 & -1.27 & -1.41 & -3.03 & -3.43 \\
\hline
\end{tabular}

Note: the error $=100 \% *($ fitted value-actual average yield $) /$ actual average yield.

number of auto regression parameters, $d$ is the order of differencing required to produce stationarity, and $q$ is the number of moving average parameters (Jensen, 1990). Both autoregressive and moving average models requires stationary data: mean and variance of the time series are constant over time. The constant mean assumption implies no cycles or trends in the data, and the constant variance assumption is similar to the homogeneity-of-variance assumption of linear regression. The order of differencing refers to the number of times each previous observation is subtracted from each successive observation until no systematic decrease or increase in the level of the series remains as it drifts. The noise in a time series drifts up and down across time. A complete representation of ARIMA model is mathematically written as formula (1):

$$
\left[1-\sum_{i=1}^{p} \phi_{i} L^{i}\right](1-L)^{d} X_{t}=\left[1+\sum_{i=1}^{q} \theta_{i} L^{i}\right] \varepsilon_{t}
$$

In formula (1), besides $p, d$ and $q$ above explained, $t$ refers to the time unit while $L$ to the lag operator, $\phi(L)$ to stationary auto-regression operator, $\theta(L)$ to reversible moving average operator, and $d \in z$ to target variable.

The autoregressive model represents a process in which the observation at time $t$ is a function of the previous observation $t-1$, while a Moving Average model represents a process in which an observation is a function of the previous random shock.

It is assumed that historic yields of world wheat be a 'time series' variable as it generally rises over time due to continuous improvement of inputs to its production through scientific and technical means. In other words, the rise of world wheat yield in a long run is of a stochastic process that hints some inevitable trend behind a large number of casual events. That is to say, potential yield of world wheat can be estimated (even only) by 'time series' approach instead of any model based on production function due to its too complicated influential factors. So ARIMA model can be used for projecting the yields of world wheat in 2019 to 2028 based on the yields from 1961 to 2018 in principle limiting the number of samples projected less than $15 \%$ of total samples. The more the samples are projected, the less reliable the projection will be; the wider the coverage is, the more accurate the projection will be. In application, the 
Table 4: The regression result of ARIMA $(1,1,1)$ model for average yields of world wheat in 2019 to 2028

\begin{tabular}{lllll}
\hline Variable & Coefficient & Std. Error & t-Statistic & Probability \\
\hline C & 0.019579 & 0.003306 & 5.923148 & 0.0000 \\
AR(1) & -0.598540 & 0.164890 & -3.629926 & 0.0006 \\
MA(1) & -0.042043 & 0.211417 & -0.198864 & 0.8431 \\
R-squared & 0.396882 & Mean dependent var & 0.018639 & \\
Adjusted R-squared & 0.374122 & S.D. dependent var & 0.052112 & \\
S.E. of regression & 0.041227 & Akaike info criterion & -3.487375 & -3.378874 \\
Sum squared resid & 0.090081 & Schwarz criterion & -3.445310 & \\
Log likelihood & 100.6465 & Hannan-Quinn criter. & 1.961834 & \\
F-statistic & 17.43830 & Durbin-Watson stat & & \\
Prob(F-statistic) & 0.000002 & & & \\
Inverted AR Roots & -0.60 & & & \\
Inverted MA Roots & 0.04 & & & \\
\hline
\end{tabular}

Table 5: The equations of five basic models for fitting top yields of world wheat from 2009 to 2018

\begin{tabular}{ll}
\hline Model & Equation \\
\hline ARMA $(1,2)$ & $\ln$ top $_{t}=0.017079+1.801354 \ln t o p_{t-1}-0.801354 \ln t o p_{t-2}+\varepsilon_{t}-1.775870 \varepsilon_{t-1}+0.913188 \varepsilon_{t-2}$ \\
ARMA $(1,1)$ & $\ln$ top $_{t}=0.014675+0.690251 \ln$ top $_{t-1}+0.309749 \ln t o p_{t-2}+\varepsilon_{t}-0.540504 \varepsilon_{t-1}$ \\
AR(1) & $\ln$ top $_{t}=0.014105+0.411273 \ln t o p_{t-1}+0.588727 \ln t o p_{t-2}+\varepsilon_{t}$ \\
MA (2) & $\ln$ top $_{t}=0.014427+\varepsilon_{t}-0.967721 \varepsilon_{t-1}+0.338629 \varepsilon_{t-2}$ \\
MA(1) & $\ln$ top $_{t}=0.014740+\varepsilon_{t}-0.671608 \varepsilon_{t-1}$ \\
\hline
\end{tabular}

Note: in the equations, 'top' stands for 'top yield of world wheat'.

projection of world wheat yields is undertaken following these steps: firstly, to produce logarithmic values of world wheat yields from 1961 to 2018 to eliminate heteroscedasticity, to test the stationarity of 'time series' and establish 'stationary series' through differencing if not stationary; secondly, to establish such five basic models as $\operatorname{ARMA}(1,2), \operatorname{ARMA}(1,1), \operatorname{AR}(1), \operatorname{MA}(2)$ and MA(1) to fit world wheat yields from 2008 to 2017 in principle equating the number of fitted samples to that of projection, and compare fitted values with actual yields to evaluate the fitness; finally, to validate and select optimum basic model used for ARIMA $(p, d, q)$ modelling to project world wheat yields in 2019 to 2028 .

\section{RESULTS AND DISCUSSION}

\section{To Project average yields of world wheat in 2019 to 2028}

Average yields of world wheat in 2019 to 2028 is projected using ARIMA model based on the yields from 1961 to 2018 .

Through testing it is shown that logarithmic series of average yields of world wheat from 1961 to 2018 is not stationary ( $\mathrm{t}$-statistic value is -1.837562 but $\mathrm{ADF}$ unit root test critical value at $1 \%$ level is -4.130526 ) while it becomes stationary after being once differenced ( $\mathrm{t}$-statistic value is -15.54040 and $\mathrm{ADF}$ unit root test critical value at $1 \%$ level is -3.552666). Thus, five basic models used for fitting average yields of world wheat from 2009 to 2018 are established on the basis of once differenced series of the yields' logarithmic values. Their equations and fitness are shown in Table 2 and Table 3, respectively.

As shown in Table 3, ARMA(1,1) basic model is used for ARIMA $(1,1,1)$ modelling to project average yields of world wheat in 2019 to 2028 because its fitness with mean error (ME) of $-1.80 \%$ is the best among five kinds.

\section{ARIMA modelling to project average yields of world wheat in 2019 to 2028}

The regression result of ARIMA $(1,1,1)$ model is shown in Table 4. Absolute values of both inverted AR root $(-0.60)$ and inverted MA root $(0.04)$ are all below 1.00 , which shows the ARIMA $(1,1,1)$ model is stationary. Therefore, 
Table 6: The error between fitted values and actual top yields of world wheat from 2009 to 2018 (\%)

\begin{tabular}{|c|c|c|c|c|c|}
\hline Year & $\operatorname{ARMA}(1,2)$ & $\operatorname{ARMA}(1,1)$ & $\mathrm{AR}(1)$ & MA (2) & MA (1) \\
\hline 2009 & -12.01 & -10.20 & -12.15 & -8.00 & -6.63 \\
\hline 2010 & -4.91 & -3.18 & -5.35 & -0.84 & +0.67 \\
\hline 2011 & -12.63 & -11.26 & -13.29 & -9.14 & -7.73 \\
\hline 2012 & -1.78 & -0.47 & -2.81 & +1.89 & +3.50 \\
\hline 2013 & -2.07 & -1.00 & -3.37 & +1.31 & +2.95 \\
\hline 2014 & -9.42 & -8.66 & -10.89 & -6.54 & -5.00 \\
\hline 2015 & -13.51 & -12.99 & -15.17 & -10.99 & -9.49 \\
\hline 2016 & -1.60 & -1.25 & -3.78 & +0.99 & +2.72 \\
\hline 2017 & -6.14 & -6.03 & -8.49 & -3.92 & -2.25 \\
\hline 2018 & +8.39 & +8.26 & +5.37 & +10.66 & +12.62 \\
\hline Mean & -5.57 & -4.68 & -6.99 & -2.46 & -0.86 \\
\hline
\end{tabular}

Note: the error $=100 \% *($ fitted value-actual top yield $) /$ actual top yield.

Table 7: The regression result of ARIMA $(0,1,1)$ model for top yields of world wheat in 2019 to 2028

\begin{tabular}{lllll}
\hline Variable & Coefficient & Std. Error & t-Statistic & Probability \\
\hline C & 0.014740 & 0.003448 & 4.275444 & 0.0001 \\
MA(1) & -0.671608 & 0.104856 & -6.405074 & 0.0000 \\
R-squared & 0.395847 & Mean dependent var & 0.012109 & \\
Adjusted R-squared & 0.384659 & S.D. dependent var & 0.095615 & \\
S.E. of regression & 0.075004 & Akaike info criterion & -2.307493 & \\
Sum squared resid & 0.303781 & Schwarz criterion & -2.235159 & \\
Log likelihood & 66.60980 & Hannan-Quinn criter. & -2.279449 & \\
F-statistic & 35.38133 & Durbin-Watson stat & 2.246638 & \\
Prob(F-statistic) & 0.000000 & $/$ & & \\
Inverted MA Roots & 0.67 & $/$ & & \\
\hline
\end{tabular}

average yields of world wheat in 2019, 2020, 2021,2022, 2023, 2024, 2025, 2026, 2027 and 2028, are projected using the ARIMA $(1,1,1)$ model and resulted with 3569 , $3640,3712,3785,3860,3936,4014,4094,4175$ and 4257 $\mathrm{kg} \mathrm{ha}^{-1}$, respectively.

\section{To project top yields of world wheat in 2019 to 2028}

Though wheat in different countries has its own climatic condition differing from the others, but those that enjoyed top yields of world wheat in some given years, represent various casual events behind which an inevitable law limits average yield meeting the top. In this case, the variation of top yields of world wheat in long term is deemed as stochastic process. This study does not aim to reveal the effect of climatic factors on the growth of wheat in any specific country owning top yield in the world, but to explore general trend of top yields of wheat on global scale.
Thus similarly, top yields of world wheat in 2019 to 2028 can be projected using ARIMA model based on the yields from 1961 to 2018.

\section{To establish and test basic models used for fitting top yields of world wheat from 2009 to 2018}

Through testing it is shown that logarithmic series of top yields of world wheat from 1961 to 2018 is not stationary ( $\mathrm{t}$-statistic value is -0.465786 but ADF unit root test critical value at $1 \%$ level is -4.140858 ) while it becomes stationary after being once differenced ( $\mathrm{t}$-statistic value is -14.06732 and ADF unit root test critical value at $1 \%$ level is -3.555023 ). Thus, five basic models used for fitting top yields of world wheat from 2009 to 2018 are established on the basis of once differenced series of the yields' logarithmic values, whose equations and fitness are respectively shown in Table 5 and Table 6. 
Table 8: Model Summary and Parameters of global warming effect on the average yield from 1961 to 2018

\begin{tabular}{|c|c|c|c|c|c|c|c|c|c|}
\hline \multirow[t]{2}{*}{ Equation } & \multicolumn{5}{|c|}{ Model Summary } & \multicolumn{4}{|c|}{ Parameter Estimates } \\
\hline & R Square & $\mathrm{F}$ & df1 & df2 & Sig. & Constant & $\mathrm{b} 1$ & b2 & b3 \\
\hline Linear & 0.793 & 214.986 & 1 & 56 & 0.000 & -15802.517 & 1269.394 & & \\
\hline Logarithmic & 0.793 & 214.454 & 1 & 56 & 0.000 & -45903.582 & 18142.430 & & \\
\hline Inverse & 0.792 & 213.275 & 1 & 56 & 0.000 & 20478.934 & -258956.435 & & \\
\hline Quadratic & 0.793 & 105.583 & 2 & 55 & 0.000 & -13410.136 & 934.611 & 11.699 & \\
\hline Cubic & 0.793 & 105.583 & 2 & 55 & 0.000 & -13410.136 & 934.611 & 11.699 & 0.000 \\
\hline Compound & 0.724 & 147.185 & 1 & 56 & 0.000 & 0.603 & 1.777 & & \\
\hline Power & 0.726 & 148.327 & 1 & 56 & 0.000 & $7.043 \mathrm{E}-7$ & 8.227 & & \\
\hline $\mathrm{S}$ & 0.727 & 149.126 & 1 & 56 & 0.000 & 15.946 & -117.577 & & \\
\hline Growth & 0.724 & 147.185 & 1 & 56 & 0.000 & -0.506 & 0.575 & & \\
\hline Exponential & 0.724 & 147.185 & 1 & 56 & 0.000 & 0.603 & 0.575 & & \\
\hline Logistic & 0.724 & 147.185 & 1 & 56 & 0.000 & 1.659 & 0.563 & & \\
\hline
\end{tabular}

Table 9: Model Summary and Parameters of global warming effect on the top yield from 1961 to 2018

\begin{tabular}{|c|c|c|c|c|c|c|c|c|c|}
\hline \multirow[t]{2}{*}{ Equation } & \multicolumn{5}{|c|}{ Model Summary } & \multicolumn{4}{|c|}{ Parameter Estimates } \\
\hline & R Square & $\mathrm{F}$ & df1 & df2 & Sig. & Constant & $\mathrm{b} 1$ & $\mathrm{~b} 2$ & b3 \\
\hline Linear & 0.712 & 138.233 & 1 & 56 & 0.000 & -41322.602 & 3413.511 & & \\
\hline Logarithmic & 0.714 & 140.040 & 1 & 56 & 0.000 & -122541.947 & 48890.046 & & \\
\hline Inverse & 0.717 & 141.550 & 1 & 56 & 0.000 & 56447.880 & -699298.853 & & \\
\hline Quadratic & 0.723 & 71.791 & 2 & 55 & 0.000 & -229529.489 & 29750.673 & -920.353 & \\
\hline Cubic & 0.723 & 71.909 & 2 & 55 & 0.000 & -168294.561 & 16742.218 & 0.000 & -21.686 \\
\hline Compound & 0.669 & 113.238 & 1 & 56 & 0.000 & 6.453 & 1.634 & & \\
\hline Power & 0.673 & 115.080 & 1 & 56 & 0.000 & $5.383 \mathrm{E}-5$ & 7.036 & & \\
\hline S & 0.676 & 116.724 & 1 & 56 & 0.000 & 15.935 & -100.719 & & \\
\hline Growth & 0.669 & 113.238 & 1 & 56 & 0.000 & 1.865 & 0.491 & & \\
\hline Exponential & 0.669 & 113.238 & 1 & 56 & 0.000 & 6.453 & 0.491 & & \\
\hline Logistic & 0.669 & 113.238 & 1 & 56 & 0.000 & 0.155 & 0.612 & & \\
\hline
\end{tabular}

As shown in Table 6, the ARIMA $(0,1,1)$ model used for projecting top yields of world wheat in 2019 to 2028 , is established on the basis of MA(1) basic model because of its best fitness with ME of $-4.68 \%$ among five kinds. Noticeably, the top yields is not as well fitted as the average yields from 2009 to 2018 according to their ME because it fluctuated more than the average.

\section{ARIMA modelling used for projecting top yields of world wheat in 2019 to 2028}

The regression result of ARIMA $(0,1,1)$ model is shown in Table 7.

As shown in Table 7, absolute value of inverted MA $\operatorname{root}(0.67)$ are below 1.00 , which shows the $\operatorname{ARIMA}(0,1,1)$ model is stationary. Thus, the top yields of world wheat in 2019, 2020, 2021, 2022, 2023, 2024, 2025, 2026, 2027 and 2028, projected using the ARIMA $(0,1,1)$ model, are to be 9852, 9998, 10146, 10297, 10449, 10604, 10761, 10920, 11082 and $11246 \mathrm{~kg} \mathrm{ha}^{-1}$, respectively.

\section{The effects of global warming on the yields of world wheat}

It is worldwide acknowledged that annual global mean temperature has been rising over time since industrial evolutionary. As above-analyzed, both average and top yields of world wheat rise over time in general. Theoretically, there must exist certain inherent relationship between annual 


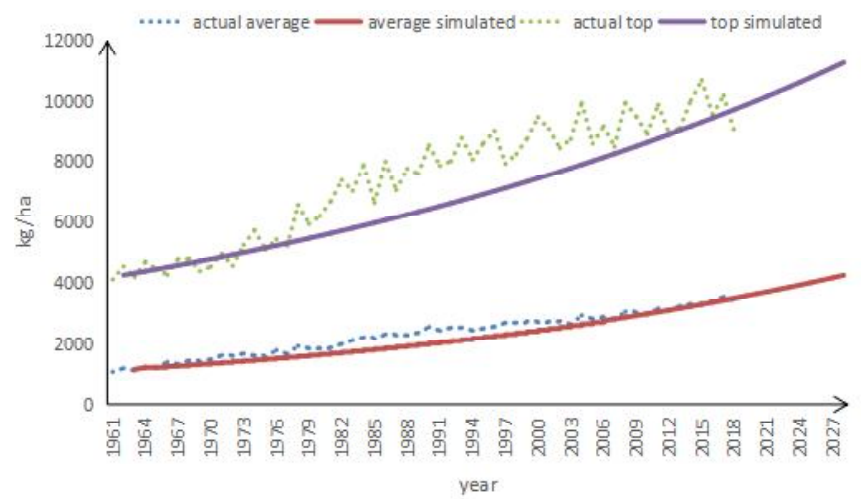

Fig. 1: Average and top yields of world wheat in 1961 to 2028

global mean temperature and the yields of world wheat because temperature is one of essential factors for wheat growth and yield. Though all climatic factors such as sunlight, temperature, precipitation and gases have their respective influences on the growth and yield of world wheat, but only the variation (rise) of annual global mean temperature is observed. Therefore, the contribution of sunlight, precipitation and gases each year at global level can be considered as constant (in modelling), to the yield of world wheat including both spring and winter varieties worldwide.

In empirical analyses: it is causality-tested that there exist Granger causalities between annual global mean temperature and average yield (with $\mathrm{P}$ of 0.0093 and FStatistic of 6.18295) and top yield (with P of 0.0499 and FStatistic of 3.30424) of world wheat from 1961 to 2018; and it is co-integration-tested that there are long-run equilibrium relationships between annual global mean temperature and average yield $(\mathrm{P}=0.0000$ while $\mathrm{t}-$ Statistic $=76.09989)$ and top yield $(\mathrm{P}=0.0434$ while $\mathrm{t}-\mathrm{Statistic}=2.068827)$ of world wheat from 1961 to 2018 . Thus, taking annual global mean temperature as independent while world wheat yield as dependent, the effect of global warming on the yields from 1961 to 2018 is respectively regression-modeled with constant and shown as in Table 8 and Table 9.

As shown in Table 8, the effect of global warming on average yield of world wheat from 1961 to 2018 is positive with coefficient $b 1$ of 18142.430 and linear function best simulated citing the highest $\mathrm{R}$ squared of 0.793 and $\mathrm{F}$ of 214.986 .

As shown in Table 9, the effect of global warming on top yield of world wheat from 1961 to 2018 is negative with

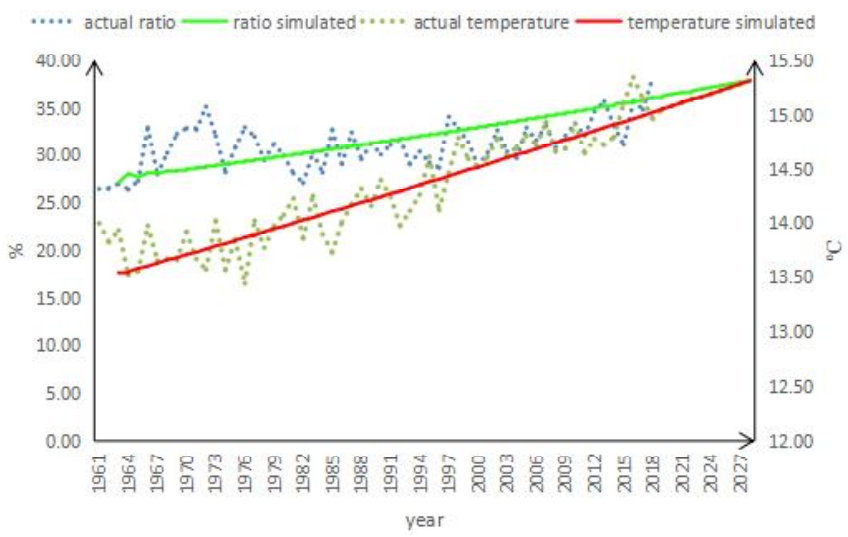

Fig. 2: The ratio (\%) of average to top of yield and annual global mean temperature $\left({ }^{\circ} \mathrm{C}\right)$ in 1961 to 2028

Note: ratio simulated $=100 *$ average yield simulated $/$ top yield simulated.

cubic function (coefficient $b 3=-21.686$ ) showing one of two highest $\mathrm{R}$ squared values (0.723) among 11 kinds and higher F of 71.909 than the other (71.791).

To see further global warming effects on the yields of world wheat in 1961 to 2028, ARIMA $(1,0,1)$ model is established with stationary logarithmic series of annual global mean temperature ( $\mathrm{t}$-statistic value $=-6.996297$ while ADF unit root test critical value at $1 \%$ level $=-4.127338$ ) and ARMA $(1,1)$ basic model with the lowest ME of $-0.08 \%$ between fitted values and actual temperatures from 2009 to 2018 among five kinds. The ARIMA $(1,0,1)$ model is used for projecting annual global mean temperature resulted with $15.05,15.08,15.11,15.14,15.16,15.19,15.22,15.25$, 15.28 and $15.31^{\circ} \mathrm{C}$ in $2019,2020,2021,2022,2023,2024$, 2025, 2026, 2027 and 2028, respectively. Then different regression models are used for simulating the dependence of world wheat yields on annual global mean temperature, which reveals that global warming exerts positive effect on average yield of world wheat with a quadratic function (coefficient b2 $=314.531$ as $\mathrm{R}^{2}=0.873$ ) while negative effect on the top yield with cubic function (coefficient of $b 3$ $=-11.733$ as $\mathrm{R}^{2}=0.798$ ). The result is consistent with the scenario from 1961 to 2018 in terms of the trend.

\section{The ratio of average to top of world wheat yields and annual global mean temperature in 1961 to 2028}

As previous-discussed, the 'top yield' is considered potential limit of the 'average yield' because the latter will chase after but never meet the former. Just as projected in this research, average yields of world wheat in 2019, 2020, 2021, 2022, 2023, 2024, 2025, 2026, 2027 and 2028 are $36.23 \%, 36.41 \%, 36.59 \%, 36.76 \%, 36.94 \%, 37.1 \%$, 
$37.30 \%, 37.49 \%, 37.67 \%$ and $37.85 \%$ of the top ones, respectively. As shown in Fig. 1, top yield of world wheat fluctuated more than the average in rise from 1961 to 2018, average yield simulated rises almost in linear trend while the top simulated does in smooth curve one in 1961 to 2028.

As shown in Fig. 2, actual ratio of average to top of world wheat yields from 1961 to 2018 rose in fluctuation ranging from $38.23 \%$ (in 2018) to $26.37 \%$ (in 1964) while the ratio simulated in 1961 to 2028 almost rises in linear trend; annual global mean temperature from 1961 to 2018 fluctuated in slight rise while the temperature simulated in 1961 to 2028 almost rises in linear trend. In the future, the average yield will increasingly approach the top partly due to positive effect on the average while negative effect on the top, of global warming.

From the years, researchers have been working hard for seeking quality yield of food crop especially staple one like wheat. Through different techniques like variety cultivation and genetic engineering techniques, the yield of wheat can be improved. Genetic engineering is regarded as the most effective way for improving the yield potential of wheat. Improving seeds through breeding and advanced cultivation should be simultaneouslyused to maximize wheat yields. However, no matter what seed improving approaches (for example cloning) or cultivation technology (for example controllable temperature) are used, there is evidence that any given crop's yield is limited due to the solar radiation limit. Unfortunately, 'low yield' and 'high quality' is often 'bundle-sold', which represents an indissoluble link e.g. when attempting to maximize wheat production means accepting an inevitable decrease in its quality. It is undeniable that under special conditions, wheat top yields can be maximized, however this will not be sustained for a long period of time. Thus in a long run, any crop's yield over time theoretically shows a trend of logistic curve (i.e. $S$-shaped curve), where the crop's yield is positively accelerated before the turn-point, while negatively accelerated after that until the acceleration stopped eventually. For the crop whose current average yield is in low place before the turnpoint of such $S$-shaped curve, the opportunities for improving global production should be mainly dependent on raising the crop yield potential in high-yield countries with high efficiency; for those in high place after the turn-point of such $S$-shaped curve, the opportunities should be mainly dependent on low-yield countries through the amelioration of arable land as top yield rises increasingly difficult over time; and for those in middle place around the turn-point of such $S$-shaped curve, the opportunities should be dependent on both high-yield and low-yield countries with integrated efficiency.

\section{CONCLUSION}

Global warming exerts positive effect on average yield of world wheat while negative one on the top yield; as for world wheat production in 2019 to 2028, the opportunities for improving production should be mainly dependent on the advantage of high-yield countries as the yield is still in low place before the turn-point of $S$-shaped curve in long-term trend affected partly by greenhouse gas effect.

\section{ACKNOWLEDGEMENT}

The research team appreciates the support provided by Climate Change Special Fund of China Meteorological Bureau (CCSF201939) for proposed study.

\section{REFERENCES}

Azad, N., Behmanesh J., Rezaverdinejad, V. and Rezaie, H.T. (2018). Climate change impacts modeling on winter wheat yield under full and deficit irrigation in MyandoabIran. Archives Agron. Soil Sci., 64(5): 731-746.

Dong, J., Lu, H.B., Wang, Y.W., Ye, T. and Yuan, W.P. (2020). Estimating winter wheat yield based on a light use efficiency model and wheat variety data. ISPRS $J$. Photogram. Rem. Sens., 160: 18-32.

Fahad, M., Ahmad, I., Rehman, M., Waqas, M.M. and Gul, F. (2019). Regional Wheat Yield Estimation by Integration of Remotely Sensed Soil Moisture into a Crop Model. Canadian J. Rem. Sens., 45(6): 770-781.

Feng, P.Y., Wang, B., Liu, D.L., Waters, C. and Yu, Q. (2019). Incorporating machine learning with biophysical model can improve the evaluation of climate extremes impacts on wheat yield in south-eastern Australia. Agric. Forest Meteorol., 275: 100-113.

Jelocnik, M., Zubovic, J. and Zdravkovic, A. (2019). Estimating impact of weather factors on wheat yields byusing panel model approach - The case of Serbia. Agric. Water Manage., 221: 493-501.

Khaliq, T., Gaydon, D.S.,Ahmad, M.U.D., Cheema, M.J.M. and Gull, U. (2019). Analyzing crop yield gaps and their causes using cropping systems modelling-A case study of the Punjab rice-wheat system, Pakistan. Field Crops Res., 232: 119-130. 
Lai, Y.R., Pringle, M.J., Kopittke, P.M., Menzies, N.W., Orton, T.G. and Dang ,Y.P. (2018). An empirical model for prediction of wheat yield, using time-integrated Landsat NDVI. Int. J. Appl. Earth Observ. Geoinform., 72: 99108.

Mistry, P. and Bora, G. (2019). Development of yield forecast model using multiple regression analysis and study of the impact of climatic parameters on spring wheat. Int. J. Agric. Biol. Engineer., 12(4): 110-115.

Qu, C.H., Li, X.X., Ju, H. and Liu, Q. (2019). The impacts of climate change on wheat yield in the Huang-Huai-Hai Plain of China using DSSAT-CERES-Wheat model under different climate scenarios. J. Integrative Agric., 18(6): 1379-1391.

Singh, P.K., Singh, K.K., Singh, P., Balasubramanian, R., Baxla, A.K., Kumar, B., Gupta, A., Rathore, L.S. and Kalra, N. (2017). Forecasting of wheat yield in various agroclimatic regions of Biharbyusing CERES-Wheat model. J. Agrometeorol., 19(4): 346-349.

Skakun, S., Vermote, E., Franch, B., Roger, J.C., Kussul, N., Ju, J.C. and Masek, J. (2019). WinterWheatYieldAssessment from Landsat 8 and Sentinel-2 Data: Incorporating Surface Reflectance, Through Phenological Fitting, into Regression Yield Models. Rem. Sensing, 11(15).

Tang, X.P., Song, N., Chen, Z.F., Wang, J.L. and He, J.Q. (2018). Estimating the potential yield and ETc of winter wheat across Huang-Huai-Hai Plain in the future with the modified DSSAT model. Sci. Reports, 8.

Tian, L.Y., Li, Z.X., Huang, J.X., Wang, L.M., Su, W., Zhang, C. and Liu, J.M. (2013). Comparison of Two Optimization Algorithms for Estimating Regional Winter Wheat Yield by Integrating MODIS Leaf Area Index and World Food Studies Model. Sensor Letters, (6-7): 1261-1268.

Wang, Y.L., Xu, X.G., Huang, L.S., Yang, G.J., Fan, L.L., Wei, P.F. and Chen, G. (2019). An Improved CASAModel for Estimating Winter Wheat Yield from Remote Sensing Images. Rem. Sensing, 11(9).

Zhang, C., Liu, J.G., Dong, T.F., Shang, J.L., Tang, M., Zhao, L.L. and Cai, H.J. (2019). Evaluation of the Simple Algorithm for Yield Estimate Model in Winter Wheat Simulation under Different Irrigation Scenarios. Agron. J., 111(6): 2970-2980. 